\title{
The Effect of Recreation in a Snow-Covered Forest Environment on the Psychological Wellbeing of Young Adults: Randomized Controlled Study
}

\author{
Ernest Bielinis ${ }^{1, *(\mathbb{D})}$, Adrian Łukowski ${ }^{2,3}{ }^{(\mathbb{D}}$, Aneta Omelan ${ }^{4}$, Sergii Boiko ${ }^{5}$, \\ Norimasa Takayama ${ }^{6}{ }^{-}$and Donald L. Grebner ${ }^{7}$ \\ 1 Department of Forestry and Forest Ecology, Faculty of Environmental Management and Agriculture, \\ University of Warmia and Mazury, Pl. Łódzki 2, 10-727 Olsztyn, Poland \\ 2 Faculty of Forestry, Poznań University of Life Sciences, Wojska Polskiego 71c, 60-625 Poznań, Poland; \\ adrian.lukowski@up.poznan.pl \\ 3 Institute of Dendrology Polish Academy of Sciences, Parkowa 5, 62-035 Kórnik, Poland \\ 4 Department of Tourism, Recreation and Ecology, Faculty of Environmental Sciences, \\ University of Warmia and Mazury, ul. Oczapowskiego 5, 10-719 Olsztyn, Poland; \\ aneta.omelan@uwm.edu.pl \\ 5 Forest Culture Center in Gołuchów, ul. Działyńskich 2, 63-322 Gołuchów, Poland; ternianyn@gmail.com \\ 6 Environmental Planning Laboratory, Department of Forest Management, Forestry and Forest Products \\ Research Institute in Japan, 1 Matsunosato, Tsukuba, Ibaraki 305-8687, Japan; hanri@ffpri.affrc.go.jp \\ 7 Department of Forestry, Mississippi State University, Box 9681, Mississippi State, MS 39762, USA; \\ dlg26@msstate.edu \\ * Correspondence: ernest.bielinis@uwm.edu.pl; Tel.: +48-603-809-211
}

Received: 2 August 2019; Accepted: 19 September 2019; Published: 20 September 2019

\begin{abstract}
Forest recreation can be successfully conducted for the purpose of psychological relaxation, as has been proven in previous scientific studies. During the winter in many countries, when snow cover occurs frequently, forest recreation (walking, relaxation, photography, etc.) is common. Nevertheless, whether forest therapy conducted in a forest environment with a snow cover will also have a positive effect on psychological indicators remains unknown. Furthermore, male subjects frequently participate in forest therapy experiments, whereas females are rarely involved. Thus, in this study, the effectuality of forest recreation during winter and with snow cover was tested on 32 young females. For these reasons, the experiment involved $15 \mathrm{~min}$ periods of relaxation in a forest environment or in an urban street environment, in addition to a pre-test under indoor conditions (randomized controlled study). Four psychological questionnaires Profile of Mood States (POMS), Positive and Negative Affect Schedule (PANAS), Restorative Outcome Scale (ROS), Subjective Vitality Scale (SVS)) were administered to participants before and after interventions. Results showed that participants' levels of negative mood, as measured by different aspects of the POMS questionnaire (tension/anxiety, anger/hostility, depression/dejection, confusion, and fatigue), decreased after exposure to the forest environment. In contrast, both tension/anxiety and anger/hostility increased in the urban street environment. The indicator of negative affect from the PANAS questionnaire also increased after exposure to the urban street environment, whereas the indicator of positive affect based on PANAS was higher in the forest environment than in the urban street environment. Restorativeness and subjective vitality exhibited higher values after exposure to the forest environment in comparison to those from the control and pre-test. The changes in these indicators demonstrate that forest recreation in the snow during winter can significantly increase psychological relaxation in females, as well as show that recreation can be successfully conducted under these winter conditions.
\end{abstract}


Keywords: deciduous forest; female; forest bathing; forest therapy; Positive and Negative Affect Schedule; Profile of Mood States; Restorative Outcome Scale; restoration; Shinrin-Yoku; snow covered forest; Subjective Vitality Scale; winter

\section{Introduction}

Forest recreation is an activity engaged for pleasure, and it is done outside in a natural forest environment [1]. One specific form of this activity is forest recreation focusing on health improvement, mainly called forest therapy (or forest bathing, or Shinrin-yoku). The importance of forest recreation for health improvement has increased in recent years, as manifested by an increase in the number of scientific publications regarding this issue. This popularity is not unfounded; many of these scientific papers have reported various positive influences of forest recreation interventions on humans with stress symptoms, both psychological and physiological [2-10]. Many positive outcomes have been reported in both males and females, including lowered negative and heightened positive mood states [11], lowered pulse rate and blood pressure [12], reduced rates of hormones involved in stress [13], increased immunological activity, and increased levels of cells responsible for cancer resistance [14]. This beneficial impact on health has been observed in Scandinavian and Asian countries, and various strategies, including forest therapy roads [15] and the forest garden Nacadia ${ }^{\circledR}$ [16], have been introduced to facilitate using the forest and nature for health recreation purposes. Knowledge concerning the management of forest environments to best achieve the purpose of forest recreation and knowledge regarding how and when to organize recreational activities are crucial for interested subjects (e.g., forest owners, foresters, and therapists).

Previous research has confirmed that forest recreation may also be successfully conducted during the winter and still exhibit beneficial effects on mental health. One previous study observed psychological relaxation in male and female participants; however, the study was conducted during a period without snow cover, and any additional effects of snow cover have not been examined [17]. Participants in preference tests positively evaluated winter landscapes of forests with snow, but the potential of this environment to induce psychological relaxation has not been determined [18]. Thus, the effectuality of forest recreation on psychological relaxation was tested in the current study. Snow in a forest may influence the visual properties of the landscape: The ground is covered, plants growing on the forest floor are not visible, the branches of standing trees are covered, and the dominant color of scenery is changed from green and brown to white. Furthermore, a layer of snow can affect the process of visual stimulation. In other studies, different indices of greens induced different effects on relaxation, with lower amounts of observed greens resulting in lower levels of relaxation in participants [19]. Thus, hypothetically, a forest covered by snow might not have the same restorative effect because greens are hidden. A lack of relaxing effect of the forest environment on respondents may therefore be expected if the forest is snow-covered. Nevertheless, standing trees continue to fill the forest environment, regardless of snow, and this could still stimulate relaxation. One of the aims of this study was therefore to test the influence of a forest with snow cover on psychological relaxation. Effects were tested with the participation of females (20.97 \pm 0.65 years) — a group which has not frequently been represented in research regarding forest recreation. This study thus provided a good opportunity to examine the influence of the forest environment on psychological relaxation in this under-represented group.

Overall, the purpose of this work was to test the hypothesis that short periods of forest recreation could induce the psychological relaxation of participants in a forest environment with snow cover. If this hypothesis is confirmed, this would suggest that forest recreation could also be successfully conducted under snowy winter conditions. To examine this hypothesis, an experiment was designed with an urban street environment as a control and a snow-covered forest environment as an experimental group. 


\section{Materials and Methods}

\subsection{Participants}

A group of 34 female students from the University of Warmia and Mazury in Olsztyn participated in this study. Females were selected over males because it is common in Poland that in the winter, females spend their free time, as well as much of their time spent with children, on walks. For this reason, we suggested that this form of activity related to staying in forest areas should be examined by this experimental study involving females. Students were recruited from one study course at the University (a non-forestry course), and participation in the study was voluntary. Two women did not want to participate in the research voluntarily. Qualified participants (32 females; mean age $=20.97$ years, standard deviation (S.D.) $=0.65$ ) were randomly assigned to one of two groups (16 persons in each): The experimental group (Group 1) and the control group (Group 2). A simple randomization method was used. To decide the appropriate sample size, the software G*Power 3.1 (University of Düsseldorf, Düsseldorf, Germany). was used. The effect size was set to 0.5, the alpha error probability value was set to 0.05 , and the power value was set to 0.95 . It was found that the total sample size should be at least 16 . To ensure a satisfactory power value, the total sample size was adjusted to 32 .

Before the experiment, participants from each group were informed that they would be asked to contribute to a research study of 'forest recreation' and informed consent was obtained. The purpose of the study was explained thoroughly after the experiment, because the authors of the research wished to omit the effect of suggestion on participants. All procedures performed in this study were in accordance with the ethical standards of the Polish Committee of Ethics in Science and with the 1964 Helsinki Declaration and its later amendments.

\subsection{Study Sites}

Before the experiment, all participants completed research questionnaires under indoor conditions in one of the classrooms at the University in Olsztyn city (north-eastern Poland). This place was also a gathering point. Afterwards, the experiment was conducted in a forest environment at the forest point (Group 1) and in an urban street environment at the urban point (Group 2). The participants reached each of these two areas by walking. The locations of the indoor, forest, and urban street environments are shown in Figure 1. The distance from the gathering point to either the urban point or the forest point was approximately $1 \mathrm{~km}$, which required 20 min of walking for participants in each group. The roads to both points were constantly flat, without any hills or other hindrances.

The indoor environment was quite warm $\left(21.5^{\circ} \mathrm{C}\right)$, exhibited no noise from outside, and did not contain any potted plants. The forest environment was located at a 20 min walk from the gathering point. A deciduous, broadleaved urban forest was selected, consisting of European beech (Fagus sylvatica L.), Pedunculate oak (Quercus robur L.), Common aspen (Populus tremula L.), and Black alder (Alnus glutinosa [L.] Gaertn.). Larger shrubs or dead wood did not interrupt the view in this area, although in some places, Norway spruce (Picea abies [L.] H. Karst) was in the shrub layer. The ground was mainly covered by snow during the experiment, and small amounts of snow were also visible on trunks. The urban street environment (urban point) was also a 20 min walk from the gathering point, near the center of Olsztyn. A particular place was selected without visible tree trunks, crowns, and any greens. In some places in the city environment, the snow dissolved and was not visible during the experiment (in the urban street environment, there was less snow in the landscape than in the forest environment.) The forest environment and urban street environment used in the experiment are shown in Figure 2. 


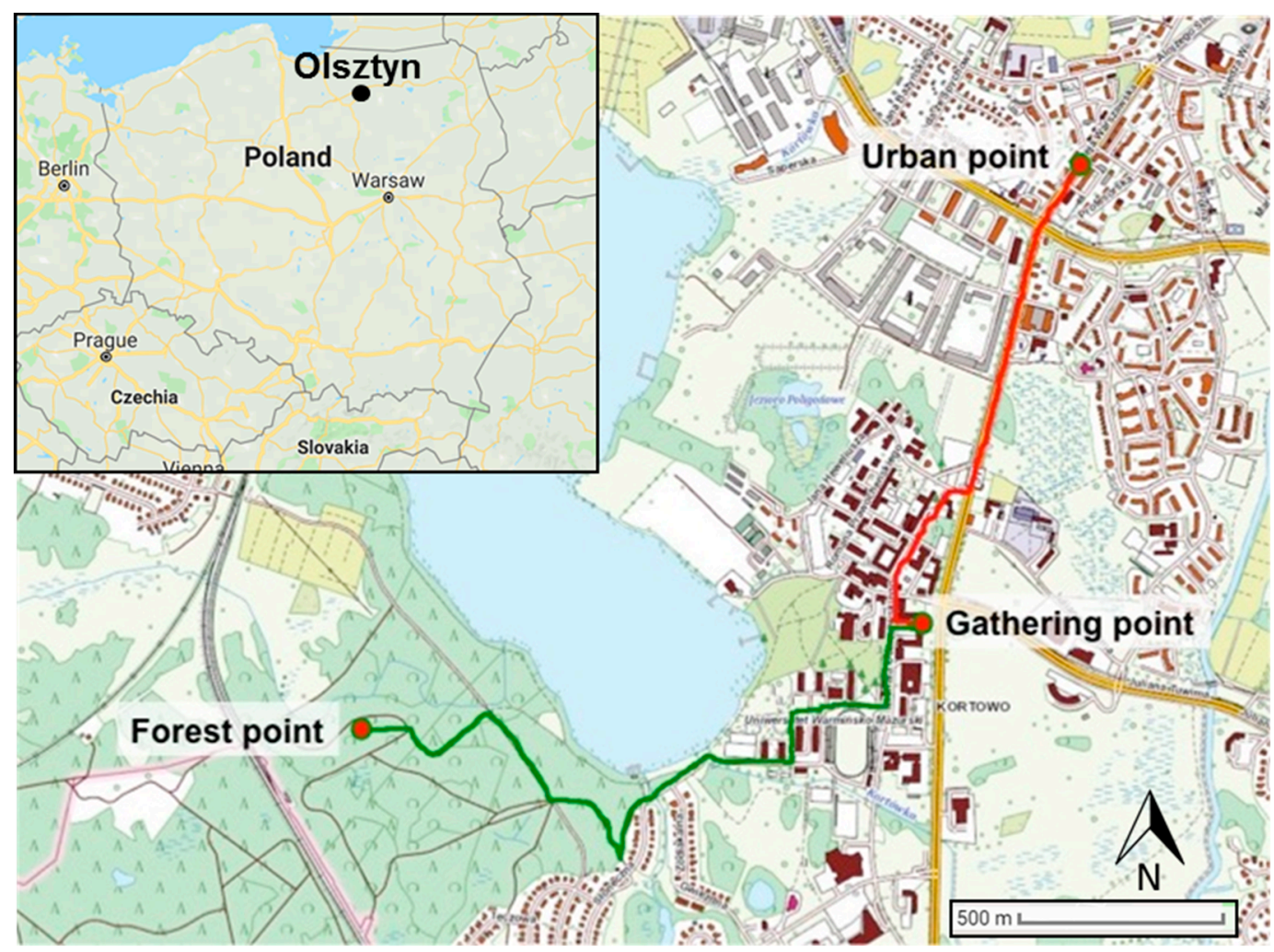

Figure 1. The map of experimental locations.
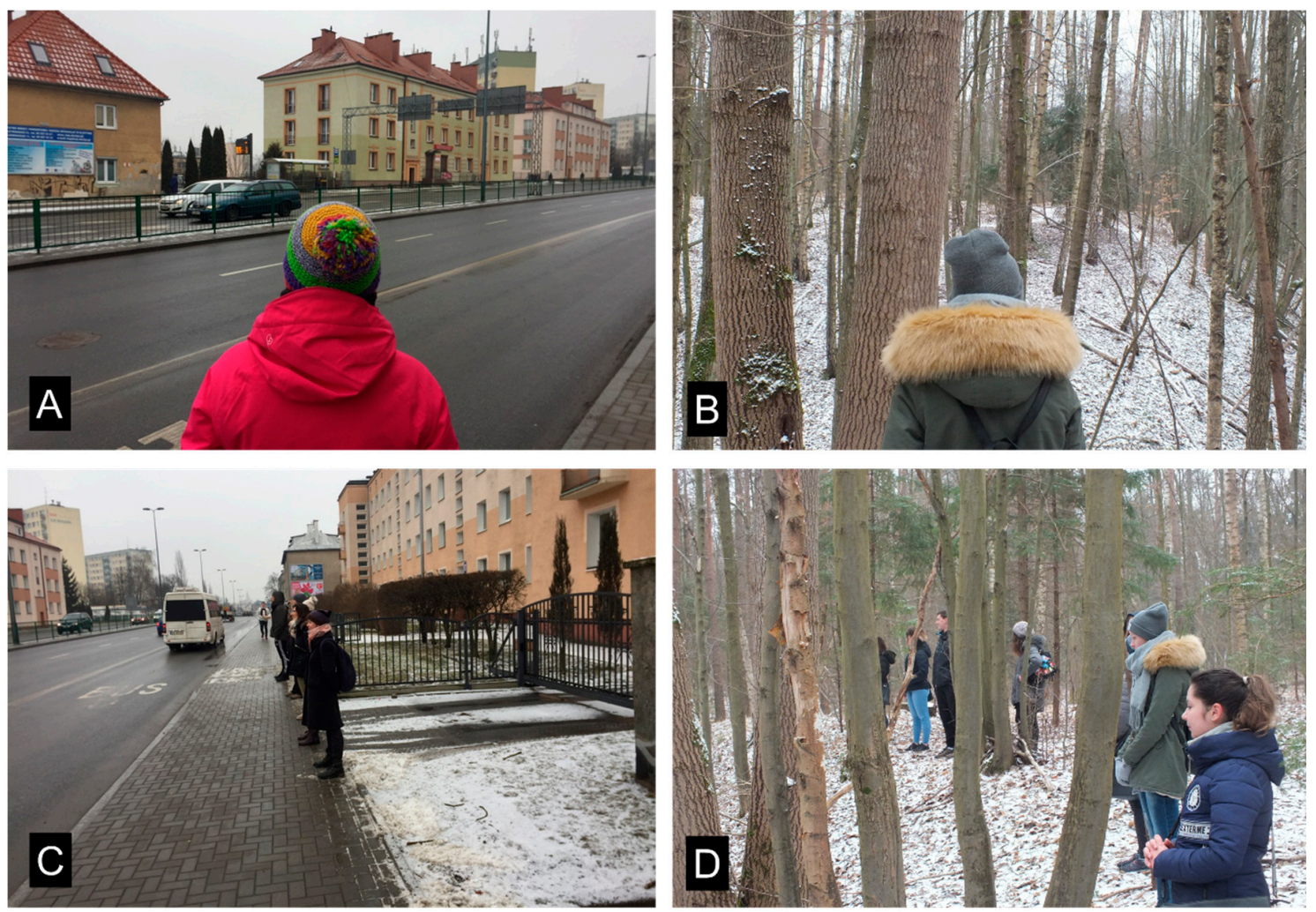

Figure 2. Photos showing the urban (A) and forest (B) views used for the viewing session. Photos of the research group during viewing sessions in the urban street environment (C) and forest environment (D). 
During the field experiment, the level of noise was measured with the application 'Sound level analyzer (SLA)' using an iPhone 6 (Apple Inc, Cupertino, CA, USA). This method of noise measure has been scientifically tested and shown to give excellent results [20]. The mean sound level ( \pm S.D.) in the urban street environment was $66.61 \pm 5.38 \mathrm{~dB}$, whereas the mean sound level in the forest environment was $37.18 \pm 5.23 \mathrm{~dB}$.

Meteorological data were not recorded in the forest and urban street environments; however, information regarding temperature, humidity, and wind speed was available from the nearest area recorded by a meteorological station. On the day of experiment, meteorological conditions were noted from the meteorological station in Olsztyn-Mazury (location: $53^{\circ} 28^{\prime} 50.0^{\prime \prime} \mathrm{N}, 20^{\circ} 56^{\prime} 10.9^{\prime \prime} \mathrm{E}$ ). The temperature was $-0.5{ }^{\circ} \mathrm{C}$, humidity was $100 \%$, cloudiness was $100 \%$, atmospheric pressure was $995 \mathrm{hPa}$, and the speed of the west wind was $9 \mathrm{~km} / \mathrm{h}$. No snow precipitation was observed, but snow cover occurred on the ground and dissolved during the day in the city.

\subsection{Psychological Measurements}

In the current study, four psychological questionnaires were used to measure the reactions of participants to the investigated environments. The Profile of Mood States (POMS) is a valid and reliable measure of negative mood states, such as psychological distress, as well as positive mood states, such as vigor [21]. This tool has been used previously to measure participants' responses to forest environments (e.g., Lee et al. [22]). POMS measures six different mood states: Tension/anxiety, depression/dejection, anger/hostility, vigor, fatigue, and confusion. Occasionally, a short version of this questionnaire is used. In this research, the regular Polish version with 65 items was applied [23]. The Positive and Negative Affect Schedule (PANAS) is another reliable and valid instrument for measuring negative (10 items) and positive (10 items) affects [24]. Its original version is in English [25], but the Polish edition was applied in the current study [26]. PANAS has also previously been used for forest environment assessment (e.g., Takayama et al. [27]). The Restorative Outcome Scale (ROS), which measures the restorative phenomenon, is a valid and reliable scale $[28,29]$ that has been used to measure restorativeness induced by the forest environment [27]. A Polish adaptation with six items was successfully developed and used in this study [17]. The Subjective Vitality Scale (SVS), which measures a participant's level of vitality, is another scale that has been shown to be reliable and valid [30]. The Polish adaptation, consisting of four items [17], was used in the current work.

In all four questionnaires that were used, the time frame 'during present moment' was applied, which allowed for the measurement of participant reactions to different environments over a relatively short time. All scales used in this study involved the Likert scale, with the response to each item noted by participants as one of a continuous series of numbers. To assess items in the POMS scale, a 0-4 Likert scale was used. For PANAS, a 1-5 scale was used, and, for ROS and SVS, a 1-7 scale was used.

The raw data from each questionnaire were applied in all further calculations. The internal consistencies and numbers of items for each scale and subscale are included in Table 1. Most of the scales used exhibited good internal consistency, with the exception of the POMS subscale 'confusion,' where internal consistency was lower (but still acceptable).

\subsection{Procedure}

The meeting with participants was planned for 6 March 2018, at 9:00 am. At this time, while at the gathering point, participants were randomly divided into one of two groups (experimental and control). Each group then completed the questionnaires at the gathering point, a classroom at the University. Afterwards, participants were asked to walk to the urban point or to the forest point, with researchers to guide this walk (two researchers per group). At the destination point, participants were asked to stand in a line, one meter apart from one another. Each participant was placed with a proper view throughout the urban street or forest environment. The viewing property for each participant was the same. While standing as described, participants were asked to relax and observe the view for $15 \mathrm{~min}$. Talking was not allowed. Relaxation during standing was applied because during 
the winter in Poland, it is too cold to relax in a seated position. People participating in the study were healthy and fit. Subjects could not be under the influence of medicine (including alcohol) during the examination. Before the test and directly during it, smoking and coffee consumption as well as the use of cell phones was prohibited. After $15 \mathrm{~min}$ of relaxation, participants were asked to fill out the questionnaires once again. The procedure followed for the experiment is also described in Table 2.

Table 1. Verification of internal consistency and number of items for each (sub)scale.

\begin{tabular}{ccc}
\hline Scales and Subscales & Number of Items & Cronbach's Alpha \\
\hline POMS & 9 & \\
Tension/Anxiety & 15 & 0.854 \\
Depression/Dejection & 12 & 0.891 \\
Anger/Hostility & 8 & 0.867 \\
Vigor & 7 & 0.829 \\
Fatigue & 7 & 0.883 \\
Confusion & & 0.794 \\
PANAS & 10 & \\
Negative & 10 & 0.881 \\
Positive & 6 & 0.832 \\
ROS & 4 & 0.921 \\
SVS & & 0.807
\end{tabular}

POMS: Profile of Mood States; PANAS: Positive and Negative Affect Schedule; ROS: Restorative Outcome Scale; SVS: Subjective Vitality Scale; $n=32$.

Table 2. Procedure followed during the experiment.

\begin{tabular}{|c|c|c|c|}
\hline Date & Time & \multicolumn{2}{|c|}{ Activity } \\
\hline \multirow[t]{9}{*}{ 2018/03/06 (Thu.) } & $\begin{array}{c}09: 00 \\
09: 15-09: 30\end{array}$ & \multicolumn{2}{|c|}{$\begin{array}{l}\text { Meeting in the gathering point and orientation } \\
\text { Random division into two groups }\end{array}$} \\
\hline & & Group 1 (control) & Group 2 (forest) \\
\hline & 09:30-09:45 & Filling in questionnaires (pretest) & Filling in questionnaires (pretest) \\
\hline & 09:45-10:05 & Walk to the city & Walk to the forest \\
\hline & 10:05-10:10 & Standing in a row in urban point & Standing in a row in forest point \\
\hline & 10:10-10:25 & $\begin{array}{l}\text { Standing and viewing at the urban } \\
\text { street environment }\end{array}$ & $\begin{array}{l}\text { Standing and viewing at the } \\
\text { forest environment }\end{array}$ \\
\hline & 10:25-10:40 & Filling in questionnaires (posttest) & Filling in questionnaires (posttest) \\
\hline & 10:40-11:05 & Return to the campus & Return to the campus \\
\hline & 11:05 & \multicolumn{2}{|c|}{ End of the experiment } \\
\hline
\end{tabular}

\subsection{Data Analysis}

The means and S.D. values were calculated in Excel (Microsoft, Redmond, WA, USA). The distribution of data was similar to the normal distribution, and this was checked by the Shapiro-Wilk test. A parametric, mixed-design ANOVA was conducted to analyze the interactions and main effects of the POMS, PANAS, ROS, and SVS scores as pre-post indicators of the psychological restorative effect of exposure to the urban street versus forest environments. After ANOVA, post-hoc comparisons using the Fisher's least significant difference (LSD) test were conducted, a method that has also been used in previous studies [31,32]. For each analysis, effect size $\eta^{2}$ was calculated, with effects set as: Small $=0.10 ;$ medium $=0.30 ;$ and large $=0.50$. All statistical analyses were conducted using SPSS Statistics Version 24 (IBM Corp., Armonk, NY, USA).

\section{Results}

\subsection{POMS}

Two types of psychological restorative effects were considered: The effect of different conditions (urban street vs. forest environment) and the effect of exposure to a different environment (pre vs. post). 
These two factors were analyzed using a mixed model ANOVA to compare the changes in the POMS scores and to analyze the interactions between factors (Table 3). For four of the six POMS indicators (tension/anxiety, depression/dejection, anger/hostility, confusion), interactions between conditions and time were found. Regarding main effects, conditions had a significant effect on anger/hostility, and time had a highly significant effect on fatigue.

The results of the Fisher's least significant difference (LSD) test comparisons showed that tension/anxiety and anger/hostility were significantly increased after participants in the urban group were exposed to the urban street environment (urban: Pre vs. post; Table 4). In contrast, tension/anxiety, depression/dejection, anger/hostility, fatigue, and confusion significantly decreased in the forest group after exposure to the forest environment (forest: Pre vs. post). All POMS indicators were similar in both the urban and forest groups before the intervention (pre: Urban vs. forest). After the intervention, all POMS indicators (except vigor) showed significantly lower values in the forest group than in the urban group (post: Urban vs. forest). 
Table 3. Results for mixed-model ANOVAs investigating Profile of Mood States (POMS) scores.

\begin{tabular}{|c|c|c|c|c|c|c|c|c|c|c|c|c|}
\hline \multirow{3}{*}{ POMS } & \multicolumn{8}{|c|}{ Main Effect } & \multirow{2}{*}{\multicolumn{4}{|c|}{$\begin{array}{c}\text { Interaction } \\
\text { Conditions } \times \text { Time }\end{array}$}} \\
\hline & \multicolumn{4}{|c|}{ Conditions: Urban vs. Forest } & \multicolumn{4}{|c|}{ Time: Pre vs. Post } & & & & \\
\hline & $F$ & $p$ & & $\eta^{2}$ & $F$ & $p$ & & $\eta^{2}$ & $F$ & $p$ & & $\eta^{2}$ \\
\hline Tension/Anxiety & 3.680 & 0.065 & - & 0.109 & 0.025 & 0.875 & - & 0.001 & 18.056 & 0.000 & $* * *$ & 0.376 \\
\hline Depression/Dejection & 0.881 & 0.355 & - & 0.029 & 0.386 & 0.539 & - & 0.013 & 7.315 & 0.011 & * & 0.196 \\
\hline Anger/Hostility & 4.500 & 0.042 & * & 0.130 & 1.185 & 0.285 & - & 0.038 & 16.198 & 0.000 & $* * *$ & 0.351 \\
\hline Vigor & 0.023 & 0.879 & - & 0.001 & 1.572 & 0.220 & - & 0.050 & 1.775 & 0.193 & - & 0.056 \\
\hline Fatigue & 2.587 & 0.118 & - & 0.079 & 9.827 & 0.004 & $* *$ & 0.247 & 3.263 & 0.081 & - & 0.098 \\
\hline Confusion & 0.718 & 0.404 & - & 0.023 & 0.273 & 0.605 & - & 0.009 & 9.172 & 0.005 & $* *$ & 0.234 \\
\hline
\end{tabular}

${ }^{* * *}: p<0.001,{ }^{* *}: p<0.01,{ }^{*} p<0.05,-:$ Not significant, mixed-design (split-plot) ANOVA; POMS: Profile of Mood States; $n=32$.

Table 4. Results of multiple comparisons of POMS scores for urban versus forest environments, as well as before and after environmental exposure.

\begin{tabular}{|c|c|c|c|c|c|c|c|c|c|c|c|c|}
\hline & \multicolumn{4}{|c|}{ Urban } & \multirow[b]{3}{*}{$p$} & & \multicolumn{4}{|c|}{ Forest } & & \\
\hline & \multicolumn{2}{|c|}{ Pre } & \multicolumn{2}{|c|}{ Post } & & & \multicolumn{2}{|c|}{ Pre } & \multicolumn{2}{|c|}{ Post } & & \\
\hline & Average & S.D. & Average & S.D. & & & Average & S.D. & Average & S.D. & $p$ & \\
\hline Tension/Anxiety & 0.85 & 0.36 & 1.33 & 0.73 & 0.007 & ** & 0.99 & 0.81 & 0.47 & 0.46 & 0.004 & $* *$ \\
\hline Depression/Dejection & 0.71 & 0.56 & 0.95 & 0.55 & 0.151 & - & 0.85 & 0.72 & 0.48 & 0.54 & 0.025 & * \\
\hline Anger/Hostility & 0.85 & 0.48 & 1.38 & 0.76 & 0.001 & ** & 0.88 & 0.67 & 0.57 & 0.39 & 0.047 & * \\
\hline Vigor & 1.93 & 0.78 & 1.91 & 0.71 & 0.956 & - & 1.75 & 0.72 & 2.15 & 0.73 & 0.077 & - \\
\hline Fatigue & 1.81 & 0.88 & 1.59 & 0.84 & 0.355 & - & 1.65 & 1.13 & 0.82 & 0.91 & 0.002 & $* *$ \\
\hline \multirow[t]{4}{*}{ Confusion } & 1.17 & 0.63 & 1.47 & 0.87 & 0.087 & - & 1.33 & 0.65 & 0.91 & 0.77 & 0.018 & $*$ \\
\hline & \multicolumn{4}{|c|}{ Pre } & & & \multicolumn{4}{|c|}{ Post } & & \\
\hline & \multicolumn{2}{|c|}{ Urban } & \multicolumn{2}{|c|}{ Forest } & & & \multicolumn{2}{|c|}{ Urban } & \multicolumn{2}{|c|}{ Forest } & & \\
\hline & Average & S.D. & Average & S.D. & $p$ & & Average & S.D. & Average & S.D. & $p$ & \\
\hline Tension/Anxiety & 0.85 & 0.36 & 0.99 & 0.81 & 0.522 & - & 1.33 & 0.73 & 0.47 & 0.46 & 0.000 & $* * *$ \\
\hline Depression/Dejection & 0.71 & 0.56 & 0.85 & 0.72 & 0.505 & - & 0.95 & 0.55 & 0.48 & 0.54 & 0.029 & * \\
\hline Anger/Hostility & 0.85 & 0.48 & 0.88 & 0.67 & 0.902 & - & 1.38 & 0.76 & 0.57 & 0.39 & 0.000 & $* * *$ \\
\hline Vigor & 1.93 & 0.78 & 1.75 & 0.72 & 0.500 & - & 1.91 & 0.71 & 2.15 & 0.73 & 0.360 & - \\
\hline Fatigue & 1.81 & 0.88 & 1.65 & 1.13 & 0.633 & - & 1.59 & 0.84 & 0.82 & 0.91 & 0.026 & * \\
\hline Confusion & 1.17 & 0.63 & 1.33 & 0.65 & 0.541 & - & 1.47 & 0.87 & 0.91 & 0.77 & 0.039 & * \\
\hline
\end{tabular}

${ }^{* * *}: p<0.001,{ }^{* *}: p<0.01,{ }^{*} p<0.05,-:$ Not significant, ANOVA-LSD test; $n=32$, POMS: Profile of Mood States. S.D.: Standard Deviation. 


\subsection{PANAS}

A mixed-model ANOVA of the PANAS data was conducted, with conditions differences and time differences used as two factors (Table 5). The results showed that an interaction occurred in the case of 'PANAS negative affect.' Regarding main effects, no statistically significant differences were found for conditions or time. The results of the multiple comparisons tests (Table 6) showed that in the case of the urban group, there was a marginal $(p=0.044)$ difference in negative affect between the preand post-tests. When comparing the urban and forest groups after the intervention (urban: Pre vs. post), a marginal effect on 'PANAS positive' was observed $(p=0.033)$, with the positive affect slightly increased in the forest environment; however, this was likely an effect of non-conservative comparison.

Table 5. Results for mixed-model ANOVAs investigating Positive and Negative Affect Schedule States (PANAS) scores.

\begin{tabular}{|c|c|c|c|c|c|c|c|c|c|c|c|c|}
\hline \multirow{3}{*}{ PANAS } & \multicolumn{8}{|c|}{ Main Effect } & \multirow{2}{*}{\multicolumn{4}{|c|}{$\frac{\text { Interaction }}{\text { Conditions } \times \text { Time }}$}} \\
\hline & \multicolumn{4}{|c|}{ Conditions: Urban vs. Forest } & \multicolumn{4}{|c|}{ Time: Pre vs. Post } & & & & \\
\hline & $F$ & $p$ & & $\eta^{2}$ & $F$ & $p$ & & $\eta^{2}$ & $F$ & $p$ & & $\eta^{2}$ \\
\hline Negative & 0.461 & 0.503 & - & 0.015 & 0.541 & 0.468 & - & 0.018 & 4.999 & 0.033 & * & 0.143 \\
\hline Positive & 1.624 & 0.212 & - & 0.051 & 0.696 & 0.411 & - & 0.023 & 3.371 & 0.076 & - & 0.101 \\
\hline
\end{tabular}

$* * *: p<0.001,{ }^{* *}: p<0.01, *: p<0.05,-:$ Not significant, mixed-model ANOVA; $n=32$, PANAS: Positive and Negative Affect Schedule States.

Table 6. Results of multiple comparisons of PANAS scores for urban street versus forest environments, as well as before and after environmental exposure.

\begin{tabular}{|c|c|c|c|c|c|c|c|c|c|c|c|c|}
\hline & \multicolumn{4}{|c|}{ Urban } & \multirow[b]{3}{*}{$p$} & & \multicolumn{4}{|c|}{ Forest } & & \\
\hline & \multicolumn{2}{|c|}{ Pre } & \multicolumn{2}{|c|}{ Post } & & & \multicolumn{2}{|c|}{ Pre } & \multicolumn{2}{|c|}{ Post } & & \\
\hline & Average & S.D. & Average & S.D. & & & Average & S.D. & Average & S.D. & $p$ & \\
\hline PANAS Negative & 1.43 & 0.42 & 1.79 & 0.64 & 0.044 & * & 1.59 & 0.72 & 1.41 & 0.51 & 0.297 & - \\
\hline \multirow[t]{4}{*}{ PANAS Positive } & 2.73 & 0.69 & 2.56 & 0.74 & 0.484 & - & 2.65 & 0.63 & 3.08 & 0.62 & 0.069 & - \\
\hline & \multicolumn{4}{|c|}{ Pre } & & & \multicolumn{4}{|c|}{ Post } & & \\
\hline & \multicolumn{2}{|c|}{ Urban } & \multicolumn{2}{|c|}{ Forest } & & & \multicolumn{2}{|c|}{ Urban } & \multicolumn{2}{|c|}{ Forest } & & \\
\hline & Average & S.D. & Average & S.D. & $p$ & & Average & S.D. & Average & S.D. & $p$ & \\
\hline PANAS Negative & 1.43 & 0.42 & 1.59 & 0.72 & 0.453 & - & 1.79 & 0.64 & 1.41 & 0.51 & 0.069 & - \\
\hline PANAS Positive & 2.73 & 0.69 & 2.65 & 0.63 & 0.753 & - & 2.56 & 0.74 & 3.08 & 0.62 & 0.033 & * \\
\hline
\end{tabular}

\section{3. $R O S$}

In the case of the ROS, a mixed-model ANOVA was used to investigate restorativeness of the two environments, with conditions and time as factors. This analysis was similar to those conducted for data from the POMS and PANAS questionnaires (Table 7). An interaction was observed between conditions and time. Regarding main effects, a significant effect of environment was observed. The results of multiple comparisons LSD tests (Table 8) showed that in the forest group, there was a significant increase in ROS scores after exposure to the forest environment (forest: Pre vs. post). Furthermore, in the forest group, values of ROS were higher after exposure to the forest environment than they were in the urban group after exposure to the urban street environment (post: Urban vs. forest).

\subsection{SVS}

A mixed-model ANOVA was conducted to compare changes in SVS scores and to analyze the interaction between factors and main effects, as was done for the POMS, PANAS, and ROS data (Table 9). As with the ROS data, an interaction was observed between conditions and time for the SVS score data. When the main effects of the conditions and time differences were analyzed, a statistically 
significant effect of conditions was confirmed, and the time effect was not significant. The results of LSD comparisons (Table 10) showed that in the forest group, SVS scores significantly increased after exposure to the forest environment. Furthermore, after exposure to the forest environment, SVS scores were higher than after exposure to the urban street environment.

Table 7. Results for mixed-model ANOVAs investigating Restorative Outcome Scale (ROS) scores.

\begin{tabular}{|c|c|c|c|c|c|c|c|c|c|c|c|c|}
\hline \multirow{3}{*}{ ROS } & \multicolumn{8}{|c|}{ Main Effect } & \multirow{2}{*}{\multicolumn{4}{|c|}{$\begin{array}{c}\text { Interaction } \\
\text { Conditions } \times \text { Time }\end{array}$}} \\
\hline & \multicolumn{4}{|c|}{ Conditions: Urban vs. Forest } & \multicolumn{4}{|c|}{ Time: Pre vs. Post } & & & & \\
\hline & $F$ & $p$ & & $\eta^{2}$ & $F$ & $p$ & & $\eta^{2}$ & $F$ & $p$ & & $\eta^{2}$ \\
\hline & 12.284 & 0.001 & $* *$ & 0.291 & 0.220 & 0.643 & - & 0.007 & 8.885 & 0.006 & $* *$ & 0.228 \\
\hline
\end{tabular}

Table 8. Results of multiple comparisons of ROS scores for urban versus forest environments, as well as before and after environmental exposure.

\begin{tabular}{|c|c|c|c|c|c|c|c|c|c|c|c|c|}
\hline & \multicolumn{4}{|c|}{ Urban } & \multirow[b]{3}{*}{$p$} & & \multicolumn{4}{|c|}{ Forest } & \multirow[b]{3}{*}{$p$} & \\
\hline & \multicolumn{2}{|c|}{ Pre } & \multicolumn{2}{|c|}{ Post } & & & \multicolumn{2}{|c|}{ Pre } & \multicolumn{2}{|c|}{ Post } & & \\
\hline & Average & S.D. & Average & S.D. & & & Average & S.D. & Average & S.D. & & \\
\hline \multirow[t]{4}{*}{ ROS } & 4.00 & 1.25 & 3.30 & 1.41 & 0.086 & - & 4.31 & 1.19 & 5.27 & 0.94 & 0.021 & $*$ \\
\hline & \multicolumn{4}{|c|}{ Pre } & & & \multicolumn{4}{|c|}{ Post } & & \\
\hline & \multicolumn{2}{|c|}{ Urban } & \multicolumn{2}{|c|}{ Forest } & & & \multicolumn{2}{|c|}{ Urban } & \multicolumn{2}{|c|}{ Forest } & & \\
\hline & Average & S.D. & Average & S.D. & $p$ & & Average & S.D. & Average & S.D. & $p$ & \\
\hline ROS & 4.00 & 1.25 & 4.31 & 1.19 & 0.468 & - & 3.30 & 1.41 & 5.27 & 0.94 & 0.000 & $* * *$ \\
\hline
\end{tabular}

Table 9. Results for mixed-model ANOVAs investigating Subjective Vitality Scale (SVS) scores.

\begin{tabular}{|c|c|c|c|c|c|c|c|c|c|c|c|c|}
\hline \multirow{3}{*}{ SVS } & \multicolumn{8}{|c|}{ Main Effect } & \multirow{2}{*}{\multicolumn{4}{|c|}{$\begin{array}{c}\text { Interaction } \\
\text { Conditions } \times \text { Time }\end{array}$}} \\
\hline & \multicolumn{4}{|c|}{ Conditions: Urban vs. Forest } & \multicolumn{4}{|c|}{ Time: Pre vs. Post } & & & & \\
\hline & $F$ & $p$ & & $\eta^{2}$ & $F$ & $p$ & & $\eta^{2}$ & $F$ & $p$ & & $\eta^{2}$ \\
\hline & 5.524 & 0.026 & * & 0.155 & 1.103 & 0.302 & - & 0.035 & 4.527 & 0.042 & * & 0.131 \\
\hline
\end{tabular}

Table 10. Results of multiple comparisons of SVS scores for urban street versus forest environments, as well as before and after environmental exposure.

\begin{tabular}{|c|c|c|c|c|c|c|c|c|c|c|c|c|}
\hline & \multicolumn{4}{|c|}{ Urban } & \multirow[b]{3}{*}{$p$} & & \multicolumn{4}{|c|}{ Forest } & \multirow[b]{3}{*}{$p$} & \\
\hline & \multicolumn{2}{|c|}{ Pre } & \multicolumn{2}{|c|}{ Post } & & & \multicolumn{2}{|c|}{ Pre } & \multicolumn{2}{|c|}{ Post } & & \\
\hline & Average & S.D. & Average & S.D. & & & Average & S.D. & Average & S.D. & & \\
\hline \multirow[t]{4}{*}{ SVS } & 3.86 & 1.52 & 3.55 & 1.29 & 0.452 & - & 4.08 & 1.23 & 5.00 & 1.12 & 0.032 & $*$ \\
\hline & \multicolumn{4}{|c|}{ Pre } & & & \multicolumn{4}{|c|}{ Post } & & \\
\hline & \multicolumn{2}{|c|}{ Urban } & \multicolumn{2}{|c|}{ Forest } & & & \multicolumn{2}{|c|}{ Urban } & \multicolumn{2}{|c|}{ Forest } & & \\
\hline & Average & S.D. & Average & S.D. & $p$ & & Average & S.D. & Average & S.D. & $p$ & \\
\hline SVS & 3.86 & 1.52 & 4.08 & 1.23 & 0.635 & - & 3.55 & 1.29 & 5.00 & 1.12 & 0.002 & $* *$ \\
\hline
\end{tabular}

${ }^{* * *}: p<0.001,{ }^{* *}: p<0.01,{ }^{*}: p<0.05,-:$ Not significant, ANOVA-LSD test; $n=32$, SVS: Subjective Vitality Scale; S.D.: Standard Deviation. 


\section{Discussion}

\subsection{Mood States}

Consistent with previous studies $[2,5,10,11,14,17,33,34]$, this study confirmed that short periods of forest recreation in a snow-covered forest (in this case: $15 \mathrm{~min}$ of relaxation in this environment) have a significant effect on the mood states of participants. The negative indices of mood states, including tension/anxiety, anger/hostility, depression/dejection, confusion, and fatigue, decreased after exposure to the forest environment. This confirms our hypothesis that this type of intervention results in a positive outcome. The positive index of mood states (vigor) did not increase after exposure, but neither did it decrease significantly. This is not consistent with a previous study [14] or another study conducted only among females [4]. Lower levels of indicators of negative mood have many positive outcomes, confirming that brief forest recreation during the winter, when snow has occurred, can be successfully conducted for the purpose of stress reduction among females. Females may, however, react differently to the forest environment than men [17], which indicates the need for further testing of these effects on both sexes.

The effect of lowering negative mood states is useful information for therapists who work with individuals living with high levels of stress, such as a highly stressful work environment. The positive effect of nature therapy on this topic is already known [6-9], but a novel element of this study was the addition of snow cover. As snow occurs in the winter in many countries, the way in which this element affects individuals requires examination. A positive effect of forest recreation was still observed with snow cover in this study, and there are several hypotheses as to why this effect was observed. It is possible that snow in the forest environment does not obstruct the view that is generally visible in this environment. Some authors suggest that some fractal dimensions are responsible for the existence of the effect of visual stimulation on mood states. For example, some kinds of natural fractals might, hypothetically, induce this positive effect [35,36], and in a snow-covered forest, these fractal dimensions are still perceivable to respondents. This stimulation during forest recreation is crucial, and this reaction of humans is possibly some special effect connected to the biophilia hypothesis [37], which states that people evolved in a natural environment and hence feel healthy in a natural environment like a forest [38].

\subsection{Positive and Negative Affect}

Previous studies have indicated that subjects exhibit a significant decrease in negative affect after forest recreation and a significant increase in positive affect $[17,27]$. In the current study, an effect on positive affect was observed, as this indicator increased in the forest environment. Negative affect did not decrease in the forest environment after the experiment, however, although it did increase after exposure to the urban street environment. These two indicators, positive and negative affect, are important in psychological research, as their usage gives researchers and therapists information concerning the mental state of participants and patients [24].

The interpretation of results regarding negative affect is similar to that of the negative mood states of POMS - any negative symptoms are not necessary, so any decrease in this effect is welcome. In this case, a lowering effect on this indicator was unfortunately not observed. In the urban street environment, an increase in negative affect was observed, possibly due to the higher level of noise in that environment [39]. Further research should compare environments with more similar levels of noise. In the case of positive affect, a difference was observed when comparing forest and urban street environments. In the forest environment, this indicator had higher values, suggesting that in the forest environment, successful recreation could be conducted with positive effects. Because positive affect increased in the forest environment, this tendency might be explained by the biophilia hypothesis $[37,38]$. 


\subsection{Restorative Outcome}

Our findings are consistent with those of previous studies [17,27], showing that restorativeness significantly increases after exposure to the forest environment. The phenomenon of restoration in the natural environment has been previously described. This effect is frequently explained by attention restoration theory [40], which states that the mental refreshment of humans, as measured by the level of restoration, increases in natural environments. This theory suggests that this mental restoration might be a natural tool of the human nervous system, one meant to naturally maintain alertness in non-safe environments, such as the forest, as opposed to safe places, such as houses and caves. Increasing thinking capacity in a natural environment could be a natural adaptation to hunting or foraging. Perhaps restoration is a mechanism in humans predisposed to save calories [41], although this hypothesis requires further investigation.

\subsection{Subjective Vitality}

Consistent with previous studies $[17,27]$, this study's findings suggest that short, 15 min periods of relaxation in a snow-covered forest during winter can have psychological benefits for subjective vitality levels. Vitality is a concept that can be measured objectively using physiological reactions or subjectively using psychological reactions [30]. In the case of the current work, subjective methods were used. The importance of factors that increase vitality is great, as a high level of vitality is connected with better accomplishments of subjects [42], and anything that increases human performance is important for society. Based on the current study, snow cover should not be a barrier to increasing vitality during recreational stays or walks in the forest. Thus, successful forest recreation in snow-covered forests may be a good activity for people interested in increasing their personal effectiveness by stimulating an increase in their own vitality.

\subsection{A Rigorous Comparison with the Previous Study}

Previously, the same areas were used to study the impact of winter forest recreation (without snow cover) on the psychological relaxation of the subjects [17]. It is worth referring to the results of these studies in this manuscript. Particular attention should be paid to comparing the impact of environments on psychological relaxation after conducting an experiment. In the case of the POMS questionnaire results, current research showed a significant difference between: Tension/anxiety $(p<0.001)$, depression/dejection $(p=0.029)$, anger/hostility $(p=0.047)$, fatigue $(p=0.002)$ and confusion (differences for these two environments are irrelevant for the 'vigor' subscales). In the previous study [17], the tension/anxiety subscale had lower values after exposure to the forest environment compared to the urban street environment, similarly to the subscale depression/dejection, anger/hostility, fatigue and confusion. The results for the 'vigor' subscales reached significantly higher values. All differences were compared at a significance level of $p<0.05$. Comparing these two studies, it can be seen that the only difference was the significance for the vigor; the forest environment, compared to urban street environment, therefore causes psychological relaxation regardless of the presence or absence of snow cover, but this impact is somewhat smaller with snow cover.

In the case of the PANAS scale, the negative aspect in current research did not differ significantly after exposure to two different environments (forest vs. urban street environment), but the positive aspect was significantly higher after exposure to the forest environment $(p=0.033)$. In studies without snow cover [17], the negative aspect was significantly lower in the forest environment and the positive aspect was significantly higher in this environment (with a significance level of $p<0.05$ ). Therefore, the forest environment without snow cover had a slightly stronger impact on the subjects.

As for the ROS and SVS scales, the ROS scale value in the study was significantly higher in the forest environment $(p<0.001)$, similarly to the SVS scale $(p=0.002)$. In the compared study [17], exactly the same tendency was observed (with a significance level of $p<0.05$ ), so the environments in both studies had similar effects on the results obtained in the ROS and SVS scales. 
Focusing on the predominance of any of the analyzed variants (snow vs. no snow) is not easy, because the demographics of the group and its numbers varied. This should be taken into consideration when interpreting these results.

\subsection{Limitations}

This study has several limitations. First, in this study, the psychological effect of relaxation while simply standing in the forest environment was measured. These effects should be measured during other activities in a forest with snow cover. In fact, some reports indicate that being involved in certain activities may harm the positive effects of nature relaxation [43]; it is therefore worth examining why some activities induce relaxation and some do not.

Second, only females (20.97 \pm 0.65 years) were involved in this study. Future studies should investigate how recreation in a snow-covered forest influences females of different age groups, as well as how this activity influences males of different ages [4,5].

Third, only psychological measurements were used in this case; the physiological effects of this activity were not considered [44].

Fourth, different respondents went to each research site. The respondents at each research point can therefore not be compared directly, meaning that the differences among individuals in the two respondent groups could have caused the significant differences observed between the urban and forest environments. In future studies, this occurrence could be eliminated by exposing respondents from the two groups to both environments in reverse order [45].

Fifth, as respondents walked to each point on foot, they would have viewed surrounding scenery before getting to either experimental point. It is therefore possible that the time period during which respondents were exposed to the stimulus was not exactly $15 \mathrm{~min}$ in length. It is worth mentioning, however, that the walks to the two analyzed environments were conducted through either the urban street environment or the forest (Figure 1), so only one environment was able to influence each group [46].

Sixth, in the planned experiments, a carryover effect could possibly have occurred, as the positive effect of forest recreation on health can persist for a longer period of time in subjects, and the tests had to be carried out as soon as possible (due to only periodic snowfall). Conducting a crossover study could therefore be burdened with a carryover effect, and the use of this research system could be abandoned. Thus, a parallel study could be carried out in which the carryover effect was avoided. In addition, such a study can be carried out in a relatively short time. This study would not compare the effects of forest recreation to the effects of conventional recreation (active control), which would not take place under forest conditions. This is a limitation of the current research and should be investigated in future work [46].

Seventh, in this study, it was assumed that snow was present in the forest landscape if $90 \%$ of the ground's surface was covered by it. It is not known, however, what amount of snow affects the psychological reactions of subjects. This requires future research.

Eighth, in the described research, it was tested whether the forest environment with the existing snow cover affects the psychological relaxation of the subjects. Indeed, it has been shown that in a forest environment with a snow cover causes a psychological relaxation effect. The aim of the study was not to compare the forest with the snow cover with the forest environment without snow cover; however, in future studies, this type of comparison could be done (including the same participants) to find out whether the snow cover in the forest environment affects another way on the subjects than the forest environment without snow cover [18].

Ninth, it will also be important to examine how different seasons, during which forest stands in the temperate climate zone change, can affect the intensity of the psychological relaxation of subjects [47]. Research regarding this should be carried out in the future.

Tenth, this paper focuses on examining the impact of a forest environment on the psychological relaxation of young adult students. In the future, it is worth investigating how forest recreation, also 
conducted in winter, can affect people of different ages and from other demographic groups (e.g., older people, and working).

Eleventh, this study did not include men, so future studies concerning recreation in a forest environment with snow cover present should include this group [5,11].

Twelfth, it is also possible that spending too much time in the forest may have a negative effect, depending on the temperature. For this reason, encouraging people to move around to stay warm may be less stressful. The effect of ambient temperature should be examined in future research [47]. It is worth noting that the physical sensations may have been different in the urban street environment than in the forest environment. This study did not measure these feelings in this experiment. It would be useful in further studies to include a measurement of physical sensations and possibly control the positioning of experimental fields to eliminate differences between environments. It is worth adding, however, that the day of the experiment was chosen so that the wind intensity was as low as possible and the differences between the environments were as small as possible.

Thirteenth, in the experiment, there was less snow in the urban street environment, but it was noticeable in this landscape. In the experiment, it was important to check whether the forest landscape with snow actually affected psychological relaxation-research confirms that this is the case. The intensity of snow occurrence in the urban landscape (in the control environment) is less important [47].

Fourteenth, the impact of phytoncides from trees growing in the forest may also be significant and are worth investigating in future studies. It is worth emphasizing that in winter, this effect may not occur (lack of photosynthesis) in comparison to forest areas in spring and summer [48].

All these limitations could likely be overcome in further experiments in the area of forest recreation research. Future studies should also test the effect of forest recreation on males and on different age groups (e.g., on elderly participants).

\section{Conclusions}

This study examined the effect of a snow-covered forest environment during winter on young females' psychological relaxation, with the urban street environment as a control. The results showed that participants' levels of negative mood indicators (tension/anxiety, anger/hostility, depression/dejection, confusion, and fatigue) decreased after exposure to a forest environment with snow cover. Furthermore, some of these indicators increased in the urban street environment (tension/anxiety and anger/hostility). An indicator of negative affect increased after exposure to the urban street environment, whereas an indicator of positive affect was higher in the forest environment than in the urban street environment. Restorativeness and subjective vitality exhibited higher values after exposure to the forest environment in comparison to both the control and pre-test. This indicates that forest recreation, during winter and with snow cover, continues to have a significant influence on the psychological relaxation of young females. These findings are important for forest therapy practitioners, as well as for individuals who want to obtain the positive effects of forest recreation. Such recreation could be successfully conducted during winter in a forest with snow cover, and there should still be a positive effect on psychological parameters.

Author Contributions: E.B. conceived and designed the experiment, conducted data analysis, and prepared the first version of the manuscript. A.Ł. consulted on the design of the experiment, and reviewed and edited the manuscript. A.O. and S.B. were responsible for the implementation of field research and minor editorial comments on the text. N.T. contributed to publication by reviewing and editing the manuscript. D.L.G. contributed to publication by reviewing and editing the manuscript and also contributed to publication by editing the content and English of the manuscript.

Funding: The publication process was supported by funds of the Poznan University of Life Sciences. The publication is co-financed within the framework of Ministry of Science and Higher Education program as "Regional Initiative Excellence" in years 2019-2022, project number 005/RID/2018/19.

Acknowledgments: The authors of this article thank Dominik Dobrzyński for technical assistance during the research. 
Conflicts of Interest: The authors declare no conflicts of interest.

\section{References}

1. Douglas, R.W. Forest Recreation, 3rd ed.; Pergamon Press: New York, NY, USA, 1982; p. 336.

2. Lee, J.; Tsunetsugu, Y.; Takayama, N.; Park, B.J.; Li, Q.; Song, C.; Komatsu, M.; Ikei, H.; Tyrväinen, L.; Kagawa, T.; et al. Influence of forest therapy on cardiovascular relaxation in young adults. Evid.-Based Compl. Alt. 2014, 834360, 1-7. [CrossRef] [PubMed]

3. Sung, J.; Woo, J.M.; Kim, W.; Lim, S.K.; Chung, E.J. The effect of cognitive behavior therapy-based "forest therapy" program on blood pressure, salivary cortisol level, and quality of life in elderly hypertensive patients. Clin. Exp. Hypertens. 2012, 34, 1-7. [CrossRef] [PubMed]

4. Ochiai, H.; Ikei, H.; Song, C.; Kobayashi, M.; Miura, T.; Kagawa, T.; Li, Q.; Kumeda, S.; Imai, M.; Miyazaki, Y. Physiological and psychological effects of a forest therapy program on middle-aged females. Int. J. Environ. Res. Public Health 2015, 12, 15222-15232. [CrossRef] [PubMed]

5. Ochiai, H.; Ikei, H.; Song, C.; Kobayashi, M.; Takamatsu, A.; Miura, T.; Kagawa, T.; Li, Q.; Kumeda, S.; Imai, M.; et al. Physiological and psychological effects of forest therapy on middle-aged males with high-normal blood pressure. Int. J. Environ. Res. Public Health 2015, 12, 2532-2542. [CrossRef] [PubMed]

6. Morita, E.; Fukuda, S.; Nagano, J.; Hamajima, N.; Yamamoto, H.; Iwai, Y.; Nakashima, T.; Ohira, H.; Shirakawa, T. Psychological effects of forest environments on healthy adults: Shinrin-yoku (forest-air bathing, walking) as a possible method of stress reduction. Public Health 2007, 121, 54-63. [CrossRef] [PubMed]

7. Jung, W.H.; Woo, J.M.; Ryu, J.S. Effect of a forest therapy program and the forest environment on female workers' stress. Urban For. Urban Gree. 2015, 14, 274-281. [CrossRef]

8. Poulsen, D.V.; Stigsdotter, U.K.; Djernis, D.; Sidenius, U. 'Everything just seems much more right in nature': How veterans with post-traumatic stress disorder experience nature-based activities in a forest therapy garden. Health Psychol. Open 2016, 3, 1-14. [CrossRef] [PubMed]

9. Tyrväinen, L.; Ojala, A.; Korpela, K.; Lanki, T.; Tsunetsugu, Y.; Kagawa, T. The influence of urban green environments on stress relief measures: A field experiment. J. Environ. Psychol. 2014, 38, 1-9. [CrossRef]

10. Tsunetsugu, Y.; Park, B.J.; Lee, J.; Kagawa, T.; Miyazaki, Y. Psychological relaxation effect of forest therapy: Results of field experiments in 19 forests in Japan involving 228 participants. Jap. J. Hyg. 2011, 66, 670-676. [CrossRef] [PubMed]

11. Song, C.; Joung, D.; Ikei, H.; Igarashi, M.; Aga, M.; Park, B.J.; Miwa, M.; Takagaki, M.; Miyazaki, Y. Physiological and psychological effects of walking on young males in urban parks in winter. J. Physiol. Anthrop. 2013, 32, 1-18. [CrossRef] [PubMed]

12. Song, C.; Ikei, H.; Miyazaki, Y. Physiological effects of nature therapy: A review of the research in Japan. Int. J. Environ. Res. Public Health 2016, 13, 1-17. [CrossRef] [PubMed]

13. Kamioka, H.; Tsutani, K.; Mutoh, Y.; Honda, T.; Shiozawa, N.; Okada, S.; Park, S.J.; Kitayuguchi, J.; Kamada, M.; Okuizumi, H.; et al. A systematic review of randomized controlled trials on curative and health enhancement effects of forest therapy. Psych. Res. Behav. Manag. 2012, 5, 85-95. [CrossRef] [PubMed]

14. Li, Q.; Kawada, T. Effect of forest therapy on the human psycho-neuro-endocrino-immune network. Jap. J. Hyg. 2011, 66, 645-650. [CrossRef] [PubMed]

15. Hanai, T. Tourism meets psychology. J. Glob. Tour. Res. 2016, 1, 89-92.

16. Sidenius, U.; Stigsdotter, U.K.; Dahl Refshauge, A. A year in the therapy forest garden Nacadia ${ }^{\circledR}$-participants' use and preferred locations in the garden during a nature-based treatment program. Alam Cipta 2015, 8, 44-53.

17. Bielinis, E.; Takayama, N.; Boiko, S.; Omelan, A.; Bielinis, L. The effect of winter forest bathing on psychological relaxation of young Polish adults. Urban For. Urban Gree. 2018, 29, 276-283. [CrossRef]

18. Tyrväinen, L.; Silvennoinen, H.; Hallikainen, V. Effect of the season and forest management on the visual quality of the nature-based tourism environment: A case from Finnish Lapland. Scand. J. For. Res. 2017, 32, 349-359. [CrossRef]

19. Choi, J.Y.; Park, S.A.; Jung, S.J.; Lee, J.Y.; Son, K.C.; An, Y.J.; Lee, S.W. Physiological and psychological responses of humans to the index of greenness of an interior space. Complement. Ther. Med. 2016, 28, 37-43. [CrossRef] [PubMed] 
20. Murphy, E.; King, E.A. Testing the accuracy of smartphones and sound level meter applications for measurement environmental noise. Appl. Acoust. 2016, 106, 16-22. [CrossRef]

21. McNair, D.M.; Maurice, L. An analysis of mood in neurotics. J. Abnorm. Soc. Psychol. 1964, 69, 620-627. [CrossRef]

22. Lee, J.; Park, B.J.; Tsunetsugu, Y.; Ohira, T.; Kagawa, T.; Miyazaki, Y. Effect of forest bathing on physiological and psychological responses in young Japanese male subjects. Public Health 2011, 125, 93-100. [CrossRef] [PubMed]

23. Dudek, B.; Koniarek, J. The adaptation of Profile of Mood States (POMS) by D.M. McNair, M. Lorr and L.F. Droppelman. Przegląd Psychologiczny 1987, 30, 753-762. (in Polish).

24. Crawford, J.R.; Henry, J.D. The Positive and Negative Affect Schedule (PANAS): Construct validity, measurement properties and normative data in a large non-clinical sample. Br. J. Clin. Psychol. 2004, 43, 245-265. [CrossRef] [PubMed]

25. Watson, D.; Clark, L.A.; Tellegen, A. Development and validation of brief measures of positive and negative affect: The PANAS scales. J. Pers. Soc. Psychol. 1998, 54, 1063. [CrossRef]

26. Brzozowski, P. Polish Adaptation of the Positive and Negative Affect Scale (PANAS) by David Watson and Lee Anna Clark; PTPPTP: Warsaw, Poland, 2010; pp. 34-113. (in Polish)

27. Takayama, N.; Korpela, K.; Lee, J.; Morikawa, T.; Tsunetsugu, Y.; Park, B.J.; Li, Q.; Tyrväinen, L.; Miyazaki, Y.; Kagawa, T. Emotional, restorative and vitalizing effects of forest and urban environments at four sites in Japan. Int. J. Environ. Res. Public Health 2014, 11, 7207-7230. [CrossRef] [PubMed]

28. Korpela, K.M.; Ylén, M.; Tyrväinen, L.; Silvennoinen, H. Determinants of restorative experiences in everyday favorite places. Health Place 2008, 14, 636-652. [CrossRef] [PubMed]

29. Korpela, K.M.; Ylén, M.; Tyrväinen, L.; Silvennoinen, H. Favorite green, waterside and urban environments: Restorative experiences and perceived health in Finland. Health Promot. Int. 2010, 25, 200-209. [CrossRef] [PubMed]

30. Ryan, R.M.; Frederick, C. On energy, personality, and health: Subjective vitality as a dynamic reflection of well-being. J. Pers. 1997, 65, 529-565. [CrossRef]

31. Pedersen, E.; Weisner, S.E.; Johansson, M. Wetland areas' direct contributions to residents' well-being entitle them to high cultural ecosystem values. Sci. Total Environ. 2019, 646, 1315-1326. [CrossRef]

32. Dobbie, M.F. Public aesthetic preferences to inform sustainable wetland management in Victoria, Australia. Landscape Urban Plan. 2013, 120, 178-189. [CrossRef]

33. Ikei, H.; Song, C.; Kagawa, T.; Miyazaki, Y. Physiological and psychological effects of viewing forest landscapes in a seated position in one-day forest therapy experimental model. Jap. J. Hyg. 2014, 69, 104-110. [CrossRef] [PubMed]

34. Joung, D.; Kim, G.; Choi, Y.; Lim, H.; Park, S.; Woo, J.M.; Park, B.J. The prefrontal cortex activity and psychological effects of viewing forest landscapes in autumn season. Int. J. Environ. Res. Public Health 2015, 12, 7235-7243. [CrossRef] [PubMed]

35. Kaiserman, J.G. Urban Nature for Well-being: Design Recommendations for Psychological Benefits in Urban Public Spaces. Ph.D. Thesis, University of Washington, Seattle, WA, USA, 2017.

36. Van Almkerk, M.; Huisman, G. Virtual Nature Environments Based on Fractal Geometry for Optimizing Restorative Effects. Environment 2018, 12, 1-11.

37. Wilson, E.O. Biophilia: The Human Bond with Other Species; Harvard University Press: Cambridge, UK, 1984; p. 160.

38. Kobayashi, H.; Song, C.; Ikei, H.; Kagawa, T.; Miyazaki, Y. Analysis of individual variations in autonomic responses to urban and forest environments. Evid.-Based Compl. Alt. 2015, 2015, 1-7. [CrossRef] [PubMed]

39. Benfield, J.A.; Bell, P.A.; Troup, L.J.; Soderstrom, N.C. Aesthetic and affective effects of vocal and traffic noise on natural landscape assessment. J. Environ. Psychol. 2010, 30, 103-111. [CrossRef]

40. Kaplan, S. The restorative benefits of nature: Toward an integrative framework. J. Environ. Psychol. 1995, 15, 169-182. [CrossRef]

41. Cheval, B.; Tipura, E.; Burra, N.; Frossard, J.; Chanal, J.; Orsholits, D.; Radel, R.; Boisgontier, M.P. Avoiding sedentary behaviors requires more cortical resources than avoiding physical activity: An EEG study. Neuropsychologia 2018, 119, 68-80. [CrossRef] [PubMed]

42. Hone, L.C.; Jarden, A.; Schofield, G.M.; Duncan, S. Measuring flourishing: The impact of operational definitions on the prevalence of high levels of wellbeing. Int. J. Wellbeing 2014, 4, 62-90. [CrossRef] 
43. Jiang, B.; Schmillen, R.; Sullivan, W.C. How to waste a break: Using portable electronic devices substantially counteracts attention enhancement effects of green spaces. Environ. Beh. 2018, 51, 1-28. [CrossRef]

44. Bielinis, E.; Bielinis, L.; Krupińska-Szeluga, S.; Łukowski, A.; Takayama, N. The Effects of a Short Forest Recreation Program on Physiological and Psychological Relaxation in Young Polish Adults. Forests 2019, 10, 34. [CrossRef]

45. Saito, H.; Horiuchi, M.; Takayama, N.; Fujiwara, A. Effects of managed forest versus unmanaged forest on physiological restoration from a stress stimulus, and the relationship with individual traits. J. Forest Res. 2019, 24, 77-85. [CrossRef]

46. Takayama, N.; Saito, H.; Fujiwara, A.; Horiuchi, M. The effect of slight thinning of managed coniferous forest on landscape appreciation and psychological restoration. Progr. Earth Planet. Sci. 2017, 4, 17. [CrossRef]

47. Bielinis, E.; Omelan, A.; Boiko, S.; Bielinis, L. The restorative effect of staying in a broad-leaved forest on healthy young adults in winter and spring. Balt. For. 2018, 24, 218-227.

48. Nam, E.S.; Uhm, D.C. Effects of phytoncides inhalation on serum cortisol level and life stress of college students. Korean J. Adult Nurs. 2008, 20, 697-706.

(C) 2019 by the authors. Licensee MDPI, Basel, Switzerland. This article is an open access article distributed under the terms and conditions of the Creative Commons Attribution (CC BY) license (http://creativecommons.org/licenses/by/4.0/). 